\title{
Single-blinded, randomized, and controlled clinical trial evaluating the effects of Omega-3 fatty acids among septic patients with intestinal dysfunction: A pilot study
}

\author{
HUAISHENG CHEN, WEI WANG, YINGCAI HONG, HUADONG ZHANG, CHENGYING HONG and XUEYAN LIU \\ Intensive Care Unit, The Second Clinical Medical College of Jinan University, \\ Shenzhen People's Hospital, Shenzhen, Guangdong 518020, P.R. China
}

Received August 24, 2015; Accepted January 20, 2017

DOI: $10.3892 /$ etm. 2017.4680

\begin{abstract}
Sepsis is a systemic inflammatory reaction, which is aggravated by aspects of the immune response that are thought to be inhibited by Omega- 3 fatty acids. The aim of the present study was to determine if Omega-3 fatty acid could modulate immunological function and improve survival rate among septic patients with intestinal dysfunction. A total of 48 mechanically ventilated patients with intestinal dysfunction were included in this prospective, randomized and single-blind clinical study. Patients were randomly divided into control (group A) and treatment groups (group B). The treatment protocol for all the participants followed the Sepsis Survival Campaign guidelines, and group B received total parenteral nutrition containing $100 \mathrm{ml}$ of Omega-3 fatty acids (containing $10 \mathrm{~g}$ refined fish oil) per day in addition to the standard treatment applied in group A. Group B had a significantly lower mortality rate compared with group A $(12.5$ vs. $41.7 \%, \mathrm{P}<0.05)$ during the 28-day follow-up. Group B also had lower Acute Physiology and Chronic Health Evaluation II scores $(\mathrm{P}<0.05)$ and lower Marshall scores $(\mathrm{P}<0.05)$ at day 7 . In addition, group $\mathrm{B}$ had a higher ratio of $\mathrm{T}$ helper to inducer lymphocytes as well as a higher ratio of CD4 to CD8 lymphocytes ( $\mathrm{P}<0.01$ for both) than group A. It was concluded that Omega-3 fatty acids improved $\mathrm{T}$ helper/inducer and CD4/CD8 ratios, and may have reduced mortality, among septic patients with intestinal dysfunction.
\end{abstract}

\section{Introduction}

Sepsis is a systemic inflammatory reaction induced by severe infections (1). This can result in detrimental immunological responses characterized by the production of inflammatory

Correspondence to: Dr Xueyan Liu, Intensive Care Unit, The Second Clinical Medical College of Jinan University, Shenzhen People's Hospital, 1017 Dong Men Bei Road, Shenzhen, Guangdong 518020, P.R. China

E-mail: luixydr@163.com

Key words: Omega-3 fatty acids, sepsis, intestinal dysfunction, clinical trial cytokines, arachidonic acid-derived eicosanoids and reactive oxygen species, and lymphocyte apoptosis (2). These factors contribute to a range of acute and chronic diseases and may lead to high mortality when they present with sepsis complicated with multiple organ dysfunction syndrome (MODS) (3). Currently, there are agents that are capable of blocking inflammatory and immunological cascades, but their efficacy and safety among septic patients have not been fully established. For example, while thymic peptide is commonly used for modulating immunological functions in septic patients, a recent systematic review that included five randomized control studies showed that thymic peptide- $\alpha 1$ did not reduce mortality rate (4). Large doses of immunoglobulin may be able to regulate immunological responses, but its effect on septic patients remains unclear (5).

There is an increasing interest in the supplementation of clinical nutrition for improving clinical outcomes (2). Omega-3 fatty acids are essential fatty acids that are commonly found in fish such as salmon and tuna. They cannot be made by the human body and must instead be supplied through food intake. Omega-3 fatty acids have been shown to prevent hyper-inflammatory processes by inhibiting both the pro-inflammatory arachidonic acid metabolites and the release of platelet-activating factor (6). Omega-3 fatty acids also reduce the production of prostaglandin E2 and thromboxane B2 from inflammatory cells $(7,8)$. However, the immunomodulatory effects of omega-3 fatty acid are less well-documented.

The aim of the current study was to determine if Omega-3 fatty acids could have a significant effect on the length of intensive care unit (ICU) stays and mortality rates among septic patients with intestinal dysfunction, and if Omega-3 fatty acids could modulate ratios of T-helper to inducer cells and CD4 to CD8 cells, which are the key immunity parameters associated with disease severity and mortality. Septic patients with intestinal dysfunction were chosen as subjects due to their high mortality rate and the relative ease of Omega-3 fatty acid administration via total parenteral nutrition (TPN).

\section{Materials and methods}

Study designs. Septic patients were prospectively enrolled in the ICU of Shenzhen People's Hospital (Shenzhen, China), 


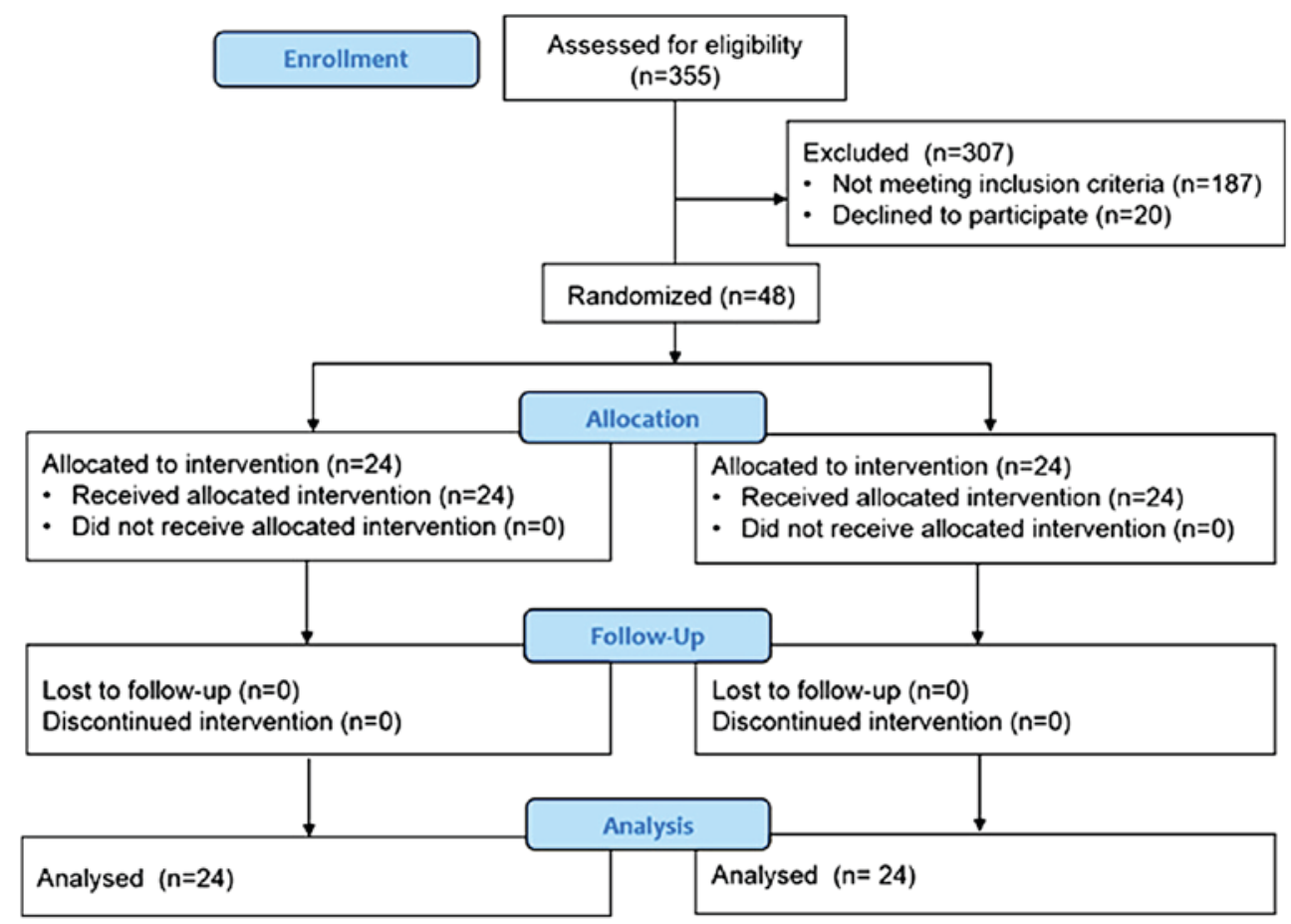

Figure 1. Flow diagram of study selection process.

from August 2011 to April 2012. The study was approved by the Medical Ethic Committee of Shenzhen People's Hospital. The study was conducted according to The Declaration of Helsinki. Written informed consent was obtained from all patients.

Study population. The eligibility of all participants admitted to the ICU was assessed using the following inclusion criteria: Aged 18 years or above; systemic inflammatory reaction syndrome caused by severe infection or trauma; Marshall score $>3$; intestinal dysfunction, abdominal infection and/or post-operation of abdominal or intestinal surgery and unable to intake nutrition via stomach and intestine; and severe infection treated with carbapenems after admission to the ICU. The exclusion criteria were: Marshall score $\geq 20$; life expectancy $<28$ days due to a chronic or incurable disease such as uncontrolled cancer; life expectancy $<24 \mathrm{~h}$; ICU stay $<7$ days after meeting inclusion criteria; or the patient having signed a 'do-not-resuscitate' form.

The definition of sepsis in the current study met the sepsis diagnosis criteria published previously (9). The diagnosis criteria of intestinal dysfunction were in accordance with the Chinese criteria of stage and severity of MODS (10). Intestinal dysfunction was classified into three severity categories: Score 1, abdominal distension and hypoactive bowel sounds; score 2, severe abdominal distention and absence of bowel sounds; and score 3, paralytic ileus and stress ulcer.

Treatment protocols and intervention. All patients received early goal-directed fluid resuscitation, mechanical ventilation and carbapenems medication, and additional antibiotics were administered according to the results of microbiological cultivation. Blood glucose control and prophylactic treatments of potential complications were also conducted. In addition, thymic peptide- $\alpha 1$ (1.6 mg via subcutaneous injection twice per day) and ulinastatin (20 million units, venous injection three times per day) were administered, and the physicians were asked to treat the patients based on the Sepsis Survival Campaign guidelines (9). All patients received a calorie intake of $20 \mathrm{kcal} / \mathrm{kg}$ per day in the first 7 days after their admission to ICU. The study participants were randomized into two groups. Patients in group B received standard TPN with $100 \mathrm{ml}$ Omega-3 fatty acids (containing $10 \mathrm{~g}$ refined fish oil) per day (Fresenius SE \& Co. KGaA, Bad Homburg, Germany). Laboratory results were obtained by taking blood samples at day 7 that were then analyzed using flow cytometry. Briefly, a Beckman Coulter EPICS ALTRA flow cytometer (Beckman Coulter, Inc., Brea, CA, USA) was used. A total of $2 \mathrm{ml}$ blood was anticoagulated using heparin (Sigma-Aldrich; Merck KGaA, Darmstadt, Germany). A $50 \mu \mathrm{l}$ sample was extracted and placed in a flow cytometer measuring probe with $20 \mu \mathrm{l}$ fluorescence marked monoclonal antibody (ab206509; 1:1,000; Abcam, Cambridge, MA, USA). The mixture was agitated and incubated at room temperature for $20 \mathrm{~min}$. A total of $2 \mathrm{ml}$ hemolysin (Sigma-Aldrich; Merck KGaA) was added and the mixture was incubated for $10 \mathrm{~min}$ at room temperature. The sample was subsequently centrifuged for $50 \mathrm{~min}$ at $157 \mathrm{x} \mathrm{g}$ at room temperature and the serum was discarded. The pellet was resuspended in $2 \mathrm{ml} \mathrm{PBS}$, and centrifuged for $5 \mathrm{~min}$ at $157 \mathrm{x}$ g at room temperature; this process was repeated twice. A fluorescent monoclonal antibody (ab206511; 1:500; Abcam) was added with $500 \mu 1$ PBS resuspension. Finally, the cells were analyzed using a FACScan system (BD Biosciences, Franklin Lakes, NJ, USA).

Randomization. The investigators referred to a manual of unique numbers generated by an independent statistician prior to the study activation to determine the study intervention for 
Table I. Clinical characteristics of the study participants.

\begin{tabular}{|c|c|c|c|c|}
\hline Variable $(\%)$ & Group A $(n=24)$ & Group B $(n=24)$ & $\chi^{2}$ & P-value \\
\hline Male & $16(66.7)$ & $18(75)$ & 0.403 & 0.53 \\
\hline Abdominal infection & $20(83.3)$ & $15(62.5)$ & 0.075 & 0.78 \\
\hline Abdominal surgery & $6(25.0)$ & $10(41.7)$ & 1.500 & 0.18 \\
\hline Use of teicoplanin medication & $7(29.2)$ & $9(37.5)$ & 0.375 & 0.38 \\
\hline Use of antifungal medication & $8(33.3)$ & $11(45.8)$ & 0.784 & 0.28 \\
\hline Hemofiltration & $3(12.5)$ & $7(29.2)$ & 2.021 & 0.14 \\
\hline
\end{tabular}

Table II. Laboratory results of the study participants at day 0.

\begin{tabular}{|c|c|c|c|c|}
\hline Variable & Group A $(n=24)$ & Group B $(n=24)$ & Z-value & P-value \\
\hline Age, years & $65.6(16.7)$ & $61.6(16.2)$ & -1.888 & 0.059 \\
\hline APACHE II score & $25.6(5.2)$ & $23.4(5.1)$ & -1.551 & 0.121 \\
\hline Marshall score & $10.3(2.1)$ & $9.8(1.6)$ & -0.976 & 0.329 \\
\hline \multicolumn{5}{|l|}{ Laboratory results } \\
\hline White blood cells (x109/1) & $15.7(7.1)$ & $15.4(7.4)$ & -0.392 & 0.695 \\
\hline Procalcitonin (ng/ml) & $5.4(3.2)$ & $4.5(3.1)$ & -0.072 & 0.942 \\
\hline Hypersensitive C-reactive protein (mg/l) & $123.7(83.5)$ & $159.9(84.1)$ & -1.549 & 0.122 \\
\hline CD3 lymphocyte (\%) & $41.2(14.1)$ & $44.3(13.4)$ & -0.619 & 0.536 \\
\hline $\mathrm{T}$ helper/inducer (\%) & $20.5(10.2)$ & $21.5(8.8)$ & -0.103 & 0.918 \\
\hline $\mathrm{T}$ suppressor $(\%)$ & $18.8(13.0)$ & $18.1(9.6)$ & -0.093 & 0.926 \\
\hline CD3/CD19 (\%) & $9.9(5.9)$ & $12.7(6.2)$ & -0.711 & 0.477 \\
\hline NK cells $(\%)$ & $14.7(9.5)$ & $13.2(7.0)$ & -0.474 & 0.635 \\
\hline CD4/CD8 (\%) & $1.3(0.7)$ & $1.5(0.9)$ & -0.330 & 0.741 \\
\hline $\operatorname{IgG}(\mathrm{g} / \mathrm{l})$ & $10.4(3.7)$ & $9.0(3.0)$ & -1.134 & 0.257 \\
\hline $\operatorname{IgA}(\mathrm{g} / \mathrm{l})$ & $2.5(1.6)$ & $1.9(1.1)$ & -1.217 & 0.224 \\
\hline $\operatorname{IgM}(\mathrm{g} / \mathrm{l})$ & $0.7(0.5)$ & $0.7(0.4)$ & -0.526 & 0.559 \\
\hline $\mathrm{C} 3(\mathrm{~g} / \mathrm{l})$ & $0.9(0.3)$ & $0.9(0.6)$ & -0.258 & 0.797 \\
\hline $\mathrm{C} 4(\mathrm{~g} / \mathrm{l})$ & $0.2(0.1)$ & $0.2(0.1)$ & -0.444 & 0.657 \\
\hline
\end{tabular}

All data are presented as the mean with standard deviation in brackets. $\mathrm{CD}$, cluster of differentiation; NK, natural killer; IgG, immunoglobulin G.

each patient. Study investigators and research coordinators were blinded to treatment allocation. The attending care nurses were aware of the treatment allocation, while the patients (and patients' families) remained unaware of the intervention throughout the trial.

Statistical analysis. Statistical analysis was performed using SPSS 19.0 (IBM SPSS, Armonk, NY, USA). Data are presented as the mean \pm standard deviation. Student's t-test and Z-test were used to analyze the difference between Group A and Group B. $\mathrm{P}<0.05$ was considered to indicate a statistically significant difference.

\section{Results}

Demographic characteristics. Between August 2011 and April 2012, 355 patients were admitted to the ICU. Of these, 48 patients who met the inclusion criteria were enrolled in the study and were randomized into two groups, each consisting of 24 patients (Fig. 1). There were no significant differences in terms of gender, abdominal infection severity or standard treatments between groups A and B (Table I). Group A and B had similar intestinal dysfunction scores $(1.79 \pm 0.59$ vs. $1.83 \pm 0.76$; $\mathrm{P}=0.833$ ). Laboratory results were also compared between the two groups and no significant differences were found (Table II).

Primary outcomes. Ten patients $(41.7 \%, 10 / 24)$ in group A succumbed to the disease, while three $(12.5 \%, 3 / 24)$ in group B succumbed during the 28-day follow-up ( $\mathrm{P}=0.023)$. For both groups, there was a decline in both the Acute Physiology and Chronic Health Evaluation II (APACHE II) and Marshall scores at 7 days after treatment began. In addition, the APACHE II and Marshall scores in group B were significantly lower than those in group $\mathrm{A}$ at day $7(\mathrm{P}<0.05$; Table III). 
Table III. APACHE II score, Marshall score and ICU stay of the study participants at day 7.

\begin{tabular}{lcccr}
\hline Variable & Group A $(\mathrm{n}=24)$ & Group B $(\mathrm{n}=24)$ & $\mathrm{t}$ value & P-value \\
\hline APACHE II score (SD) & $21.5(8.9)$ & $16.1(6.1)$ & 2.435 & $0.019^{\mathrm{a}}$ \\
Marshall score (SD) & $8.6(4.3)$ & $6.2(2.5)$ & 2.325 & $0.026^{\mathrm{a}}$ \\
ICU stay (days, SD) & $24.4(23.2)$ & $13.8(9.9)$ & 2.055 & $0.046^{\mathrm{a}}$
\end{tabular}

${ }^{\text {a }}<0.05$ vs. group $\mathrm{A}$. SD, standard deviation; ICU, intensive care unit.

Table IV. Comparison of laboratory results at day 7.

\begin{tabular}{|c|c|c|c|c|}
\hline Variable & Group A $(n=24)$ & Group B $(n=24)$ & $\mathrm{Z}$ value & P-value \\
\hline White blood cells $\left(\times 10^{9} / \mathrm{L}\right)$ & $13.9(5.1)$ & $13.1(3.5)$ & -0.381 & 0.703 \\
\hline Procalcitonin (ng/ml) & 2.6 & 0.6 & -1.794 & 0.073 \\
\hline Hypersensitive C-reactive protein (mg/l) & $74.2(56.42)$ & $63.3(38.3)$ & -0.278 & 0.781 \\
\hline CD3 lymphocyte (\%) & $46.4(14.73)$ & $51.1(15.2)$ & -1.299 & 0.194 \\
\hline T helper/inducer (\%) & $24.3(10.50)$ & $35.3(8.9)$ & -3.423 & $0.001^{\mathrm{a}}$ \\
\hline T suppressor $(\%)$ & $18.0(9.12)$ & $15.8(6.5)$ & -0.505 & 0.613 \\
\hline CD3/CD19 (\%) & $11.6(7.93)$ & $13.7(7.5)$ & -1.031 & 0.302 \\
\hline NK cells $(\%)$ & $15.6(9.05)$ & $12.3(5.9)$ & -1.227 & 0.220 \\
\hline CD4/CD8 (\%) & $1.6(1.08)$ & $2.6(1.0)$ & -3.300 & $0.001^{\mathrm{a}}$ \\
\hline $\operatorname{IgG}(\mathrm{g} / \mathrm{l})$ & $10.5(4.51)$ & $9.1(4.2)$ & -1.227 & 0.220 \\
\hline $\operatorname{IgA}(\mathrm{g} / \mathrm{l})$ & $2.9(1.94)$ & $2.0(0.9)$ & -1.547 & 0.122 \\
\hline $\operatorname{IgM}(\mathrm{g} / \mathrm{l})$ & 0.6 & 0.7 & -1.011 & 0.312 \\
\hline C3 (g/l) & $0.8(0.32)$ & $0.9(0.4)$ & -1.176 & 0.240 \\
\hline $\mathrm{C} 4(\mathrm{~g} / \mathrm{l})$ & 0.2 & 0.3 & -1.383 & 0.167 \\
\hline
\end{tabular}

All data are provided as the man with standard deviation in brackets. ${ }^{a} \mathrm{P}<0.01$ vs. Group A.

Secondary outcomes. Levels of white blood cells, procalcitonin (PCT), hypersensitive C-reactive protein (hsCRP) and other laboratory outcomes reflecting immunologic function are listed in Table IV. Changes in cells, protein levels, and health scores are presented in Figs. 2 and 3. In group B, from day 1 to 7 , there were significant increases in the ratio of $\mathrm{T}$ helper to inducer cells $(\mathrm{P}<0.01$; Fig. $2 \mathrm{Ab})$ and the ratio of CD4 to CD8 cells ( $\mathrm{P}<0.01$; Fig. 2Bb). There were also significant decreases in PCT $(\mathrm{P}<0.01$; Fig. $2 \mathrm{Cb})$, hsCRP $(\mathrm{P}<0.01$; Fig. 2Db), APACHE II scores ( $\mathrm{P}<0.01$; Fig. 3Ab) and Marshall scores $(\mathrm{P}<0.01$; Fig. $3 \mathrm{Bb})$ between day 0 and 7 in group $\mathrm{B}$.

In group $\mathrm{A}$, however, the ratio of $\mathrm{T}$ helper to inducer cells significantly decreased instead of increased ( $\mathrm{P}<0.05$; Fig. 2Aa) and there was no significant change in the ratio of CD4 to CD8 cells (Fig. 2Ba) or the level of PCT (Fig. 2Ca) between day 0 and day 7. There was a significant reduction in hsCRP in group $\mathrm{A}$, but this result was less significant than in group $\mathrm{B}(\mathrm{P}=0.003$ and $\mathrm{P}<0.0001$ respectively; Fig. 2Da). There was also a significant reduction in APACHE II score in group A, but this result was less significant than in group $\mathrm{B}(\mathrm{P}=0.045$ and $\mathrm{P}<0.0001$ respectively; Fig. 3Aa). The Marshall score did not change significantly in group A (Fig. 3Ba).

When comparing the measurements between groups $\mathrm{A}$ and $\mathrm{B}$ at day 7 , group $\mathrm{B}$ had a significantly higher ratio of $\mathrm{T}$ helper to inducer lymphocytes and a significantly higher ratio of CD4 to CD8 lymphocytes than Group A ( $\mathrm{P}<0.01$ for both; Table IV).

\section{Discussion}

Sepsis is a systemic inflammatory reaction induced by severe infection and is a common cause of MODS (11). Previous studies have shown that Omega-3 fatty acids could reduce inflammation and lower the risk of chronic diseases such as heart disease and arthritis $(12,13)$. The current study provides new evidence in support of the beneficial effect of Omega-3 fatty acids. The results suggest they could help modulate immunological responses and potentially reduce mortality rate among septic patients with intestinal dysfunction.

The average mortality rate during the 28-day follow-up for all the participants in the present study was $27.1 \%$, which was similar to that reported in a previous study (14). The mortality rate of the control group was $41.7 \%$ (10/24), despite the fact that all patients received sepsis resuscitation bundle treatment. This was probably due to the small sample size and/or different healthcare conditions to those in the previous study. Compared with the control group, patients who received Omega-3 fatty acids had a significantly lower mortality rate $(12.5 \%, 3 / 24)$ and a significantly shorter ICU stay by day 28 , suggesting a 
Aa

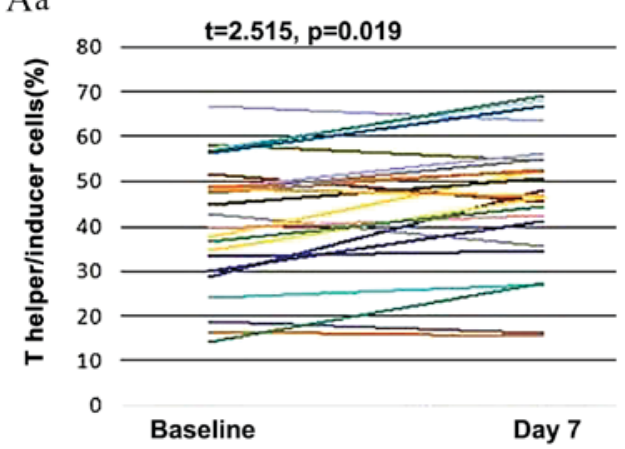

$\mathrm{Ba}$

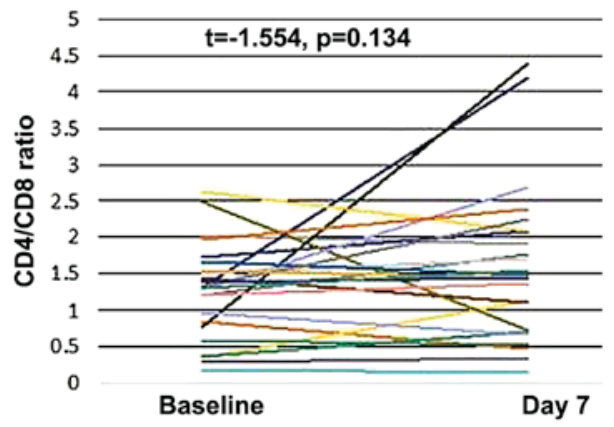

$\mathrm{Ca}$
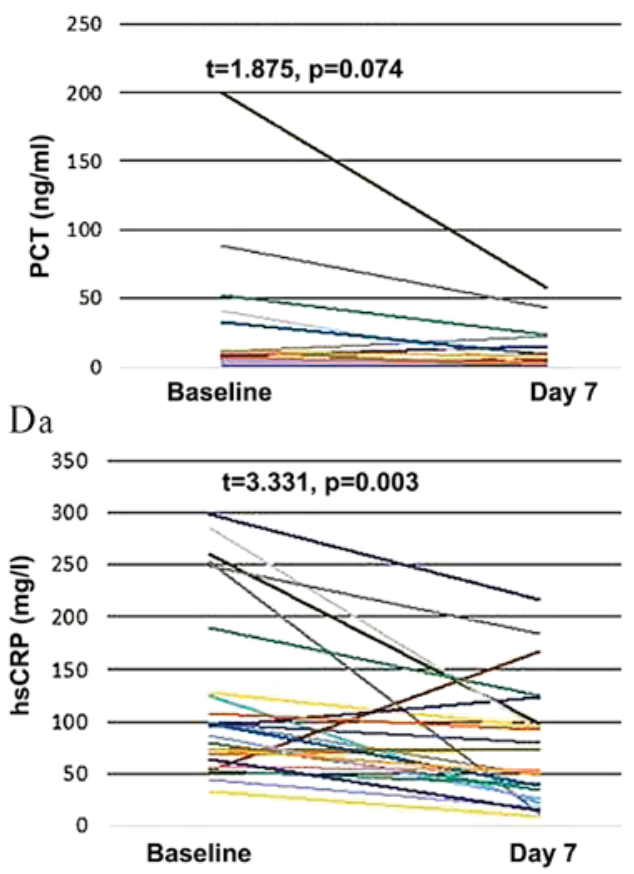

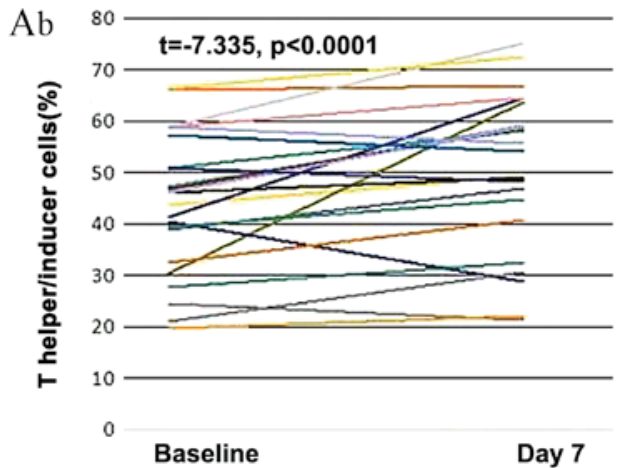

$\mathrm{Bb}$

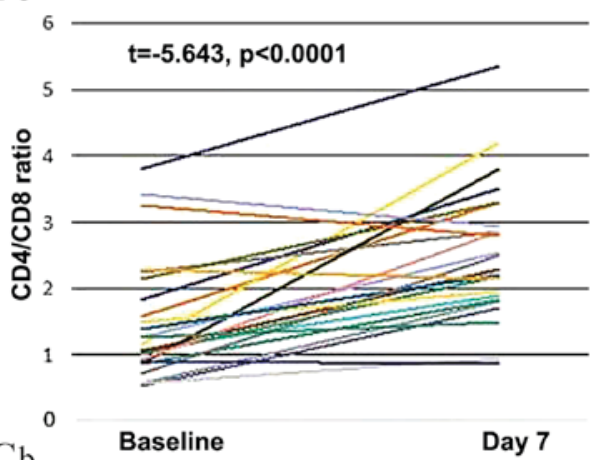

$\mathrm{Cb}$

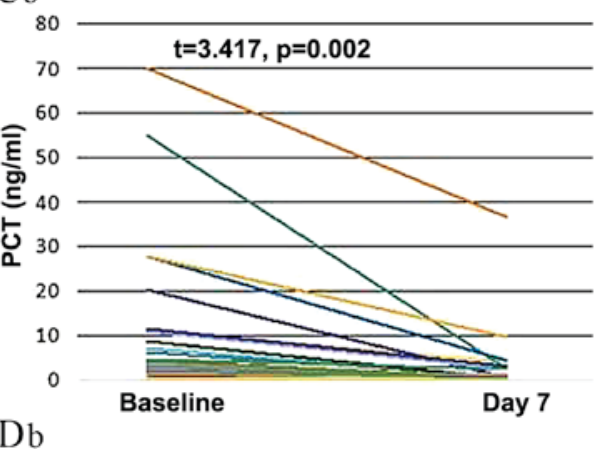

$\mathrm{Db}$

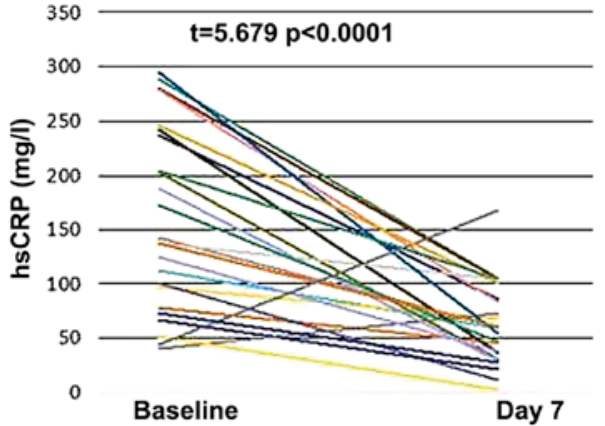

Figure 2. Changes in the levels of ( $\mathrm{Aa}$ and $\mathrm{Ab}$ ) $\mathrm{T}$ helper/inducer, (Ba and $\mathrm{Bb}$ ) CD4/CD8, (Ca and $\mathrm{Cb}$ ) PCT and (Da and Db) hsCRP from day 0 to 7. Left panel, control group; right panel, treatment group. PCT, procalcitonin; hsCRP, hypersensitive C-reactive protein.

therapeutic function of Omega-3 fatty acids for patients with sepsis. In addition, the APACHE II and Marshall scores for the experimental group at day 7 were also significantly lower compared with the control group.

The target organ of Omega-3 fatty acid treatment is still unclear thus far. Previous studies investigating the effects of Omega-3 fatty acids on inflammatory bowel disease symptoms have produced mixed results (15). Previous results have suggested that Omega-3 fatty acids have beneficial effects on renal function and could reduce the demand for renal replacement treatment (16). In addition, Omega-3 fatty acids appear to improve liver and pancreas function in post-operative cancer patients (17).

Intestinal dysfunction in septic patients is a common condition that is associated with mortality, but a validated definition of intestinal dysfunction has not been established $(18,19)$. The long-held notion that sepsis is not a distinct inflammatory disorder has been challenged (20). Rather, an understanding of sepsis will require the immunological mechanisms of cellular and organ disorders to be identified.

In the current study, the ratio of $T$ helper to inducer cells at day 7 was significantly higher in the treatment group compared 

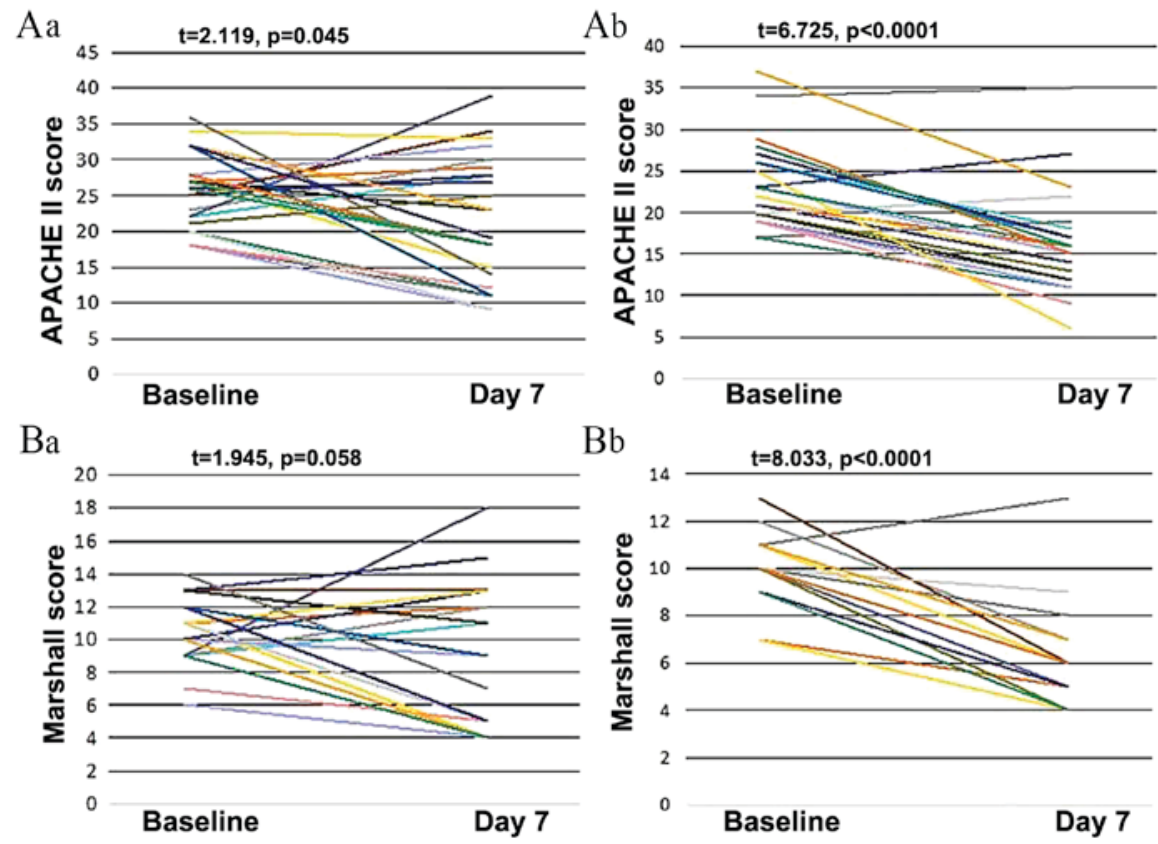

Figure 3. Changes in (Aa and $\mathrm{Ab}$ ) APACHE II and (Ba and Bb) Marshall Scores from day 0 to 7. Left panel, control group; right panel, treatment group. APACHE II, Acute Physiology and Chronic Health Evaluation II.

with the control. Consistent with this, previous animal experiments found that $\mathrm{CD} 4{ }^{+} \mathrm{T}$ lymphocytes and the ratio of $\mathrm{CD} 4$ to $\mathrm{CD} 8$ cells were significantly lower in septic rats compared with the controls (21). Furthermore, immunomodulation therapy has been found to increase $\mathrm{CD} 4^{+} \mathrm{T}$ lymphocytes for animals with sepsis (22).

In the present study, Omega-3 fatty acids appeared to have no effect on levels of immunoglobulin and complements (C3 and C4). However, an animal study showed an increasing level of immunoglobulin $\mathrm{G}$ in chickens fed with polyunsaturated fatty acids (23). Thus, further studies are needed to investigate whether Omega-3 fatty acids could improve immunoglobulin levels among patients with sepsis. Other immunomodulatory functions of Omega-3 fatty acids include reducing interleukin-1, -2 and -6 , reducing secretion and release of cytokines such as tumor necrosis factor $(24,25)$, and promoting phagocytosis of macrophages and leukocytes (26). Therefore, Omega-3 fatty acids may serve as an immune supportive agent for patients with sepsis and MODS, resulting in improved immune function and better clinical outcomes.

Sepsis is known to be caused by an uncontrolled inflammatory response. Excessive activation of the inflammatory response results in impairment of CD4 $\mathrm{T}$ lymphocytes in patients with sepsis (27). CD4 T lymphocytes include two major populations, Th1 and Th2 cells. Th1 cells can inhibit the secretion of cytokine, and Th2 cells can evoke an anti-inflammatory response (22). Omega-3 fatty acids in fish oil have beneficial effects on septic patients by inhibiting the expression of inflammatory cytokines (26), and by blocking the pathways of nuclear factor $\kappa \mathrm{B}$ and Toll-like receptor 4 (28). In a previous study, septic rat models that were pre-treated with Omega-3 fatty acids in fish oil showed an increased percentage of peripheral blood lymphocyte CD4 cells and an increased ratio of CD4 to CD8 cells (29). HsCRP is an acute phase response protein and its level inversely correlates with the prognosis of patients with sepsis (30). In the current study, hsCRP levels were slightly lower in the treatment group compared with the control at day 7 (Table IV). Omega-3 fatty acids may also modulate inflammation by reducing the synthesis of prostaglandin E2 through the arachidonic acid metabolism pathway (31). In summary, there is evidence to suggest that Omega-3 fatty acids serve a function in inhibiting inflammation (26). However, their effect may have been overridden by other anti-inflammatory medicines (e.g., ulinastatin) and has not been conclusively demonstrated.

Serum PCT is a useful diagnostic indicator for various infections. For instance, serum PCT levels increase significantly in patients with bacteremia (32-36). In the current study, PCT levels in both the treatment and control groups decreased at day 7. However, they were lower in the treatment group than the control group, suggesting that Omega-3 fatty acids may help to increase the efficacy of antibiotics.

The major limitation of the current study is that it was not possible to monitor the adverse effects of Omega-3 fatty acid treatment, given the current sample size. No significant harmful effects were noted in the current study, but there is some evidence that Omega-3 fatty acid treatment may be harmful for patients with acute lung injury (37).

In summary, septic patients with intestinal dysfunction may have immunodeficiencies. Omega-3 fatty acids may be able to modulate immune function in order to counter these deficiencies and reduce mortality. Large-scale randomized controlled trials will need to be conducted in order to confirm the current findings.

\section{Acknowledgements}

The authors would like to acknowledge Ms. Xiu-li Wen and Ms. Ya-ying Zhou for their technical support in flow cytometry. We would also like to thank Dr Yu-Cheng Chen (West 
China Hospital, Sichuan University) and Dr Yuan-yang Wang (Emergency Intensive Care Unit of Shenzhen People's Hospital) for editing the manuscript.

\section{References}

1. Hotchkiss RS and Karl IE: The pathophysiology and treatment of sepsis. N Engl J Med 348: 138-150, 2003.

2. Hosny M, Nahas R, Ali S, Elshafei SA and Khaled H: Impact of oral omega-3 fatty acids supplementation in early sepsis on clinical outcome and immunomodulation. Egyptian J Crit Care Med 1: 119-126, 2013.

3. Tinsley KW, Grayson MH, Swanson PE, Drewry AM, Chang KC, Karl IE and Hotchkiss RS: Sepsis induces apoptosis and profound depletion of splenic interdigitating and follicular dendritic cells. J Immunol 171: 909-914, 2003.

4. Yu Y, Tian JH, Yang KH and Zhang P: Evaluation of efficacy of thymosin alphal in the treatment of sepsis: A systematic review. Zhongguo Wei Zhong Bing Ji Jiu Yi Xue 21: 21-24, 2009 (In Chinese).

5. Tugrul S, Ozcan PE, Akinci O, Seyhun Y, Cagatay A, Cakar N and Esen F: The effects of Igm-enriched immunoglobulin preparations in patients with severe sepsis [ISRCTN28863830]. Crit Care 6: 357-362, 2002.

6. Calder PC: Omega-3 fatty acids and inflammatory processes. Nutrients 2: 355-374, 2010

7. Andersson A, Fenhammar J, Weitzberg E, Sollevi A, Hjelmqvist $\mathrm{H}$ and Frithiof R: Endothelin-mediated gut microcirculatory dysfunction during porcine endotoxaemia. Br J Anaesth 105: 640-647, 2010

8. Martin JM and Stapleton RD: Omega-3 fatty acids in critical illness. Nutr Rev 68: 531-541, 2010.

9. Levy MM, Dellinger RP, Townsend SR, Linde-Zwirble WT, Marshall JC, Bion J, Schorr C, Artigas A, Ramsay G, Beale R, et al: The surviving sepsis campaign: Results of an international guideline-based performance improvement program targeting severe sepsis. Crit Care Med 38: 367-374, 2010.

10. Dong J, Zhang SW and Wang BE: Intestinal dysfunction and multiple organ dysfunction syndrome. Chin Crit Care Med (issue 12): 764-767, 2005 (In Chinese).

11. Gillejohnson P, Hansson KE and Gårdlund B: Severe sepsis and systemic inflammatory response syndrome in emergency department patients with suspected severe infection. Scand J Infect Dis 45: 186-193, 2013.

12. Mori TA: Omega-3 fatty acids and cardiovascular disease: Epidemiology and effects on cardiometabolic risk factors. Food Funct 5: 2004-2019, 2014.

13. Simopoulos AP: The importance of the omega-6/omega-3 fatty acid ratio in cardiovascular disease and other chronic diseases. Exp Biol Med (Maywood) 233: 674-688, 2008.

14. Shiramizo SC, Marra AR, Durão MS, Paes ÂT, Edmond MB and Pavão dos Santos OF: Decreasing mortality in severe sepsis and septic shock patients by implementing a sepsis bundle in a hospital setting. Plos One 6: e26790, 2011.

15. Barbalho SM, Goulart Rde A, Quesada K, Bechara MD and de Carvalho Ade C: Inflammatory bowel disease: Can omega-3 fatty acids really help? Ann Gastroenterol 29: 37-43, 2016.

16. Fassett RG, Gobe GC, Peake JM and Coombes JS: Omega-3 polyunsaturated fatty acids in the treatment of kidney disease. Am J Kidney Dis 56: 728-742, 2010.

17. Heller AR, Rössel T, Gottschlich B, Tiebel O, Menschikowski M, Litz RJ, Zimmermann T and Koch T: Omega-3 fatty acids improve liver and pancreas function in postoperative cancer patients. Int J Cancer 111: 611-616, 2004.

18. Wohlmuth C, Dünser MW, Wurzinger B, Deutinger M, Ulmer H, Torgersen C, Schmittinger CA, Grander W and Hasibeder WR: Early fish oil supplementation and organ failure in patients with septic shock from abdominal infections: A propensity-matched cohort study. JPEN J Parenter Enteral Nutr 34: 431-437, 2010.
19. Li G, Li YS and Li JS: Acute bowel injury and acute intestinal distress syndrome: New concept of intestinal dysfunction. Chang Wai Yu Chang Nei Ying Yang 17: 302-305, 2010.

20. Carré JE and Singer M: Cellular energetic metabolism in sepsis: The need for a systems approach. Biochim Biophys Acta 1777: 763-771, 2008

21. Huang S, Guan X, Chen J, Ou-yang B, Yang C and Chen M: The role of immunomodulation on immune function and prognosis in sepsis. Zhongguo Pu Tong Wai Ke Za Zhi: 926-931, 2009.

22. Huang S, Guan X, Chen J, Ou-yang B, Yang C and Liu Y: Immunomodulation effect on neutrophil leukocyte and lymphocyte subsets in septic rats. Zhonghua Pu Tong Wai Ke Xue Wen Xian 3: 362-365, 2009.

23. Wang YW, Field CJ and Sim JS: Dietary polyunsaturated fatty acids alter lymphocyte subset proportion and proliferation, serum immunoglobulin g concentration, and immune tissue development in chicks. Poult Sci 79: 1741-1748, 2000.

24. Grimble RF and Tappia PS: Modulation of pro-inflammatory cytokine biology by unsaturated fatty acids. Z Ernahrungswiss 37 (Suppl 1): S57-S65, 1998.

25. Hsu CS, Chiu WC, Yeh CL, Hou YC, Chou SY and Yeh SL: Dietary fish oil enhances adhesion molecule and interleukin-6 expression in mice with polymicrobial sepsis. Br J Nutr 96: 854-860, 2006

26. Lopez-Garcia E, Schulze MB, Manson JE, Meigs JB, Albert CM, Rifai N, Willett WC and Hu FB: Consumption of (n-3) fatty acids is related to plasma biomarkers of inflammation and endothelial activation in women. J Nutr 134: 1806-1811, 2004

27. Guo L, Song Z, Li M, Wu Q, Wang D, Feng H, Bernard P, Daugherty A, Huang B and Li XA: Scavenger receptor bi protects against septic death through its role in modulating inflammatory response. J Biol Chem 284: 19826-19834, 2009.

28. Singer P, Shapiro H, Theilla M, Anbar R, Singer J and Cohen J: Anti-inflammatory properties of omega-3 fatty acids in critical illness: Novel mechanisms and an integrative perspective. Intensive Care Med 34: 1580-1592, 2008.

29. Calder PC: The relationship between the fatty acid composition of immune cells and their function. Prostaglandins Leukot Essent Fatty Acids 79: 101-368, 2008.

30. Chen B, Ni D and Zhang G: The role of early monitoring of CRP on evaluating severe sepsis. Shandong Yi Yao: 94-95, 2010.

31. Barton RG, Wells CL, Carlson A, Singh R, Sullivan JJ and Cerra FB: Dietary omega-3 fatty acids decrease mortality and kupffer cell prostaglandin E2 production in a rat model of chronic sepsis. J Trauma 31: 768-774, 1991.

32. Castelli GP, Pognani C, Cita M and Paladini R: Procalcitonin as a prognostic and diagnostic tool for septic complications after major trauma. Crit Care Med 37: 1845-1849, 2009.

33. Jongwutiwes U, Suitharak K, Tiengrim S and Thamlikitkul V: Serum procalcitonin in diagnosis of bacteremia. J Med Assoc Thai 92 (Suppl 2): S79-S87, 2009.

34. Ko YC, Wu WP, Hsu CS, Dai MP, Ou CC and Kao CH: Serum and pleural fluid procalcitonin in predicting bacterial infection in patients with parapneumonic effusion. J Korean Med Sci 24: 398-402, 2009

35. Mofidi R, Suttie SA, Patil PV, Ogston S and Parks RW: The value of procalcitonin at predicting the severity of acute pancreatitis and development of infected pancreatic necrosis: Systematic review. Surgery 146: 72-81, 2009.

36. Viñas Trullen X, Rodríguez López R, Porta Pi S, Salazar Terceros D, Macarulla Sanz E, Besora Canal P, Alvarez Tellez F, Iglesias Castro C and Feliu Palá X: Prospective study of procalcitonin as a diagnostic marker of the severity of secondary peritonitis. Cir Esp 86: 24-28, 2009 (In Spanish).

37. Rice TW, Wheeler AP, Thompson BT, de Boisblanc BP, Steingrub J and Rock P; NIH NHLBI Acute Respiratory Distress Syndrome Network of Investigators: Enteral omega-3 fatty acid, gamma-linolenic acid, and antioxidant supplementation in acute lung injury. JAMA 306: 1574-1581, 2011. 